\title{
A CADEIA PRODUTIVA DE UVAS E VINHOS DE SANTA CATARINA: UMA ANÁLISE DAS TRANSAÇÕES ENTRE OS SEUS SEGMENTOS
}

\author{
Luiz Carlos de Carvalho Junior \\ Mariana Mossini²
}

\begin{abstract}
Resumo
Este trabalho teve como objetivo identificar as características das transações entre os segmentos da cadeia produtiva vitivinícola de Santa Catarina. A fundamentação teórica utilizada foi a Teoria dos Custos de Transação. Foram coletadas informações em trabalhos existentes sobre a cadeia e foram realizadas entrevistas com especialistas de instituições e dirigentes de empresas atuantes na cadeia. Foi constatado que nas regiões tradicionais predomina a compra de insumos via mercado, o que eleva os custos de transação e abre precedente a comportamentos oportunistas de agentes envolvidos. Por outro lado, na nova região produtora, as empresas adotam a integração vertical à montante, devido à especificidade dos ativos necessários para a elaboração de vinhos finos.
\end{abstract}

Palavras-chaves: Vitivinicultura; estruturas de governança; cadeias produtivas Agroindustriais,

Classificação JEL: Q13.

\section{INTRODUÇÃO}

De acordo com estimativas do Instituto Brasileiro do Vinho (IBRAVIN), o consumo de vinho per capita no Brasil que atualmente é de 1,8 litros/ano,

Professor do Departamento de Economia e Relações Internacionais da UFSC.

Economista, graduada pela UFSC. 
deverá aumentar para 9 litros per capita/ano até 2022. Tal estimativa se deve à divulgação do volume de vendas registradas entre janeiro e fevereiro de 2007 pela União Brasileira de Vitivinicultura (UVIBRA) e pelo IBRAVIN. Segundo os números divulgados, somente nos dois primeiros meses de 2007 foram vendidos 11,7 milhões de litros de vinho no país - mais que o dobro das vendas registradas no mesmo período de 2006 (IBRAVIN, 2007).

O Rio Grande do Sul ocupa a posição de maior pólo vitivinícola do país, sendo responsável por aproximadamente $50 \%$ do volume de uvas cultivadas e $90 \%$ do total de vinhos elaborados no Brasil. Sua principal região produtora é a Serra do Nordeste, que abriga os municípios de Bento Gonçalves e Caxias do Sul, principais pólos vitivinícolas do estado.

Em Santa Catarina, as condições naturais e a imigração originaram pólos de exploração vitivinícola, como o Vale do Rio do Peixe, no meio oeste catarinense. Mais recentemente, a cidade de São Joaquim vem despontando como pólo vitivinícola na serra catarinense, concentrando 180 hectares de uvas vitis viníferas, próprias para a produção de vinhos finos. A viticultura vem se expandindo também no oeste do estado, nas microrregiões de Chapecó, São Miguel do Oeste e Concórdia onde estão sendo plantados centenas de hectares de uvas, por meio de agricultura familiar, visando amenizar as sucessivas perdas de renda com a produção de grãos.

Embora Santa Catarina seja responsável por apenas 4\% da produção brasileira de uvas, estando em sexto lugar no ranking nacional de produtores, o estado ocupa a segunda posição como maior produtor nacional de vinhos.

A cadeia produtiva da vitivinicultura é composta pelos seguintes segmentos: fornecedores de insumos; cultivo de uvas; produção de vinhos; atacado e varejo. O comportamento dos agentes econômicos no que se refere ao seu posicionamento na cadeia produtiva depende de características das transações entre os distintos segmentos que compõem a cadeia. Desta forma, estes agentes podem recorrer à integração vertical, ao mercado ou à parceria para obter as suas matérias-primas ou para distribuir os seus produtos.

O objetivo deste trabalho é analisar as transações existentes entre os elos da cadeia produtiva de vitivinicultura de Santa Catarina. Deve ser ainda ressaltado que a importância da realização deste trabalho reside na escassez de estudos sobre esta cadeia no estado catarinense, e também nas transformações recentes ocorridas na mesma com resultados significativos na qualidade dos vinhos produzidos. 


\section{REFERENCIAL TEÓRICO}

\subsection{Cadeia de produção}

Segundo Malassis apud Silva (1996) a noção de cadeia de produção ou filière agroindustrial se reporta aos itinerários seguidos por um determinado produto dentro do sistema de produção-transformação-distribuição e aos diferentes fluxos que a ele estão ligados. Para Malassis, o estudo de filière compreende dois principais aspectos, a sua identificação (o produto, seus itinerários, agentes e operações) e a análise dos mecanismos de regulação (estrutura de funcionamento dos mercados, a intervenção do Estado, etc.).

De acordo com Batalha (2001) uma cadeia de produção agroindustrial pode ser segmentada, de jusante a montante, em três macrossegmentos:

a) Comercialização. Representa as empresas que mantém contato com o cliente final da cadeia, viabilizando tanto o consumo, quanto o comércio dos produtos finais, tendo como exemplo nas cadeias agroindustriais os supermercados, restaurantes, cantinas, entre outros. Neste macrossegmento podem ser incluídas empresas responsáveis somente pela logística de distribuição dos produtos.

b) Industrialização. Este macrossegmento diz respeito às firmas responsáveis pela transformação das matérias-primas em produtos finais. $\mathrm{O}$ consumidor pode tanto ser uma agroindústria, quanto uma unidade familiar.

c) Produção de matérias-primas. Reúne as firmas fornecedoras de matérias-primas iniciais para que outras empresas avancem no processo de produção do produto final, como por exemplo, agricultura, pecuária e pesca.

O modo como se define a estrutura de uma cadeia de produção agroindustrial deve situar-se sempre de jusante a montante; segundo essa lógica, as condicionantes impostas pelo consumidor final são os principais indutores de mudanças no sistema. Nesse ponto, não se ignorar o fato de que as unidades produtivas dos sistemas também são responsáveis, por exemplo, pela introdução de inovações tecnológicas capazes de apontarem mudanças na dinâmica de funcionamento das cadeias agroindustriais. No entanto, tais 
mudanças somente serão sustentáveis quando reconhecidas pelo consumidor como fonte de diferenciação em relação a situação de equilíbrio anterior.

Morvan apud Zylbersztajn e Neves (2000) apresenta a noção do uso múltiplo do conceito de cadeia. Segundo o autor, o conceito pode ser utilizado tanto para fins de análise e descrição do sistema, como ferramenta de gestão, aplicada à definição de estratégias no plano da firma, ou no apoio à elaboração de políticas governamentais.

\subsection{Economia dos Custos de Transação (ECT)}

A teoria dos custos de transação teve a sua origem nos anos 30 com Ronald Coase, sendo complementada e aprimorada nos anos 70 por Oliver Williamson. De acordo com este último autor, tal teoria poderia indicar a forma organizacional mais adequada para efetuar uma transação, em função da situação dos atributos observados na transação, de forma a minimizar os custos de transação (PESSALLI e FERNANDEZ, 2001, p.101).

Os custos de transação podem ser definidos como "os custos ex-ante de esboçar, negociar e salvaguardar um acordo e, sobretudo, os custos ex-post decorrentes de problemas de adaptação que surgem quando a execução de um contrato é imprecisa como resultado de atrasos, erros ou omissões" (FARINA et al., 1997, p.283).

As transações diferem umas das outras, sendo este o fundamental motivo para explicar a existência de diferentes estruturas de governança que irão reger tais negociações. A existência dessa diversidade contratual é explicada, sobretudo, pelas diferenças básicas nas características das transações. A adequação da firma às diversas estruturas de governança tem como principal função a redução dos custos de transação.

Segundo Williamson apud Zylbersztajn e Neves (2000), Fianni (2002) e Azevedo (2000) ao realizarem trocas, os agentes engajam-se em transações, as quais se distinguem por três atributos básicos, conforme a seguir:

c) Freqüência. Diz respeito ao número de vezes que os agentes envolvidos realizam determinadas transações, algumas ocorrem em um único ponto no tempo, enquanto outras são recorrentes. Transações entre empresas, ou dentro de uma mesma empresa se dão com freqüência, de modo que pode passar a ser economicamente viável a construção de um mecanismo 
contratual que as oriente. A repetição de uma transação possibilita que as partes adquiram conhecimento umas das outras, reduzindo-se dessa forma a incerteza, e que, além disso, se construa uma reputação entre os agentes em torno de um compromisso confiável com o objetivo de continuidade da relação.

d) Incerteza. Está associada a efeitos não previsíveis. A impossibilidade de previsão de choques que possam alterar as características dos resultados da transação. A complexidade que a incerteza impõe à elaboração de contratos implica na ocorrência de lacunas contratuais, deixando os agentes sujeitos a atitudes oportunistas, o que eleva os custos da transação.

e) Especificidade dos ativos. Ativos específicos são aqueles que não poderão ser reutilizados sem que incorram perdas de valor. Isso significa dizer que uma ou ambas as partes envolvidas na transação perderão caso esta não se concretize. Quanto maior a especificidade, maiores serão os riscos e problemas de adaptação, o que implica maiores custos de transação. Os ativos podem apresentar diferentes tipos de especificidades, dentre as mais comuns destacam-se as especificidades de localização, tempo, capital humano e ativos dedicados. A primeira associa-se a perda de valor no caso de deslocamento físico. Como exemplo, pode-se citar a proximidade de firmas pertencentes a uma mesma cadeia produtiva, o que reflete em economia nos custos de transporte e armazenagem. No caso da especificidade temporal, o valor de uma transação depende sobretudo do tempo em que ela se processa, sendo especialmente relevante no caso da negociação de produtos perecíveis. A especificidade de capital humano está ligada ao conhecimento acumulado pelos indivíduos em determinadas atividades que não possuirão aplicabilidade em outras empresas. Os ativos dedicados compreendem ativos físicos produzidos especificamente para um determinado fim, não sendo possível seu reaproveitamento em outras atividades.

\subsubsection{Características dos agentes}

O ponto de partida para a existência de custos de transação é o reconhecimento de que os agentes econômicos são limitadamente racionais e oportunistas. Considerando-se a racionalidade limitada, os contratos serão 
incompletos visto que será impossível aos agentes prever todas as possibilidades de contingências futuras inerentes aos mesmos. Por outro lado, deve-se considerar também o oportunismo, que sujeita as partes envolvidas nas transações ao comportamento antiético das demais.

Segundo Simon apud Farina et al. (1997) os sujeitos agem racionalmente, porém de forma limitada. Tal limitação decorre da complexidade do ambiente que cerca as decisões dos agentes, que em função disso, não conseguem atingir a racionalidade plena. Caso os agentes dispusessem de informações simétricas e contassem com plena racionalidade, os contratos formulados seriam completos, e dessa forma, não haveria a necessidade de se estruturar formas sofisticadas de governança.

O princípio da existência de oportunismo entre os agentes implica que as partes possam se aproveitar de uma renegociação, agindo antieticamente, impondo perdas às demais. No entanto, identificam-se três principais motivos para a continuidade dos contratos. O primeiro é a reputação, conceito que representa uma motivação pecuniária, visto que o custo de rompimento do contrato pode implicar em perdas que superam sua manutenção. O segundo motivo são as garantias legais, ou seja, a existência de mecanismos punitivos instituídos pela sociedade que atuam como desestimuladores para a quebra contratual oportunista. Os princípios éticos completam as motivações à continuidade dos contratos. Tais contratos são guiados a partir dos códigos de conduta definidos pelos indivíduos envolvidos na transação, tratando-se de contratos tácitos de difícil monitoramento.

\subsubsection{Estruturas de governança}

Williamson apud Zylbersztajn e Neves (2000) propõe que a firma, vista como uma estrutura de governança das transações, pode definir se tratará determinado contrato a partir de uma pura relação de mercado, se preferirá a forma mista contratual ou se definirá a necessidade de integração vertical, a partir dos princípios de minimização dos custos de produção, somados aos custos de transação.

Conforme pode-se observar no quadro 01, a melhor forma de governança surge a partir da interação entre as características das transações com os pressupostos comportamentais. O princípio da racionalidade limitada e 
os contratos incompletos possibilitam a elaboração de contratos que contemplem as possibilidades futuras.

Quadro 01 - Alinhamento dos contratos

\begin{tabular}{|c|c|c|c|c|}
\hline \multirow{5}{*}{ 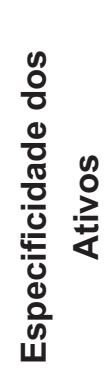 } & \multicolumn{4}{|c|}{ Incerteza } \\
\hline & & Baixa & Média & Alta \\
\hline & Baixa & Mercado & Mercado & Mercado \\
\hline & Média & Contrato & $\begin{array}{c}\text { Contrato ou } \\
\text { Integração Vertical }\end{array}$ & $\begin{array}{c}\text { Contrato ou } \\
\text { Integração Vertical }\end{array}$ \\
\hline & Alta & Contrato & $\begin{array}{c}\text { Contrato ou } \\
\text { Integração Vertical }\end{array}$ & Integração Vertical \\
\hline
\end{tabular}

Fonte: Brickley, Smith e Zimmerman (1997) apud Zylbersztajn e Neves (2000).

A organização de formas eficientes de governança deve considerar os princípios da racionalidade limitada, do comportamento oportunístico, da especificidade dos ativos e definir pelo maior ou menor controle das transações. Nos casos onde a especificidade dos ativos é baixa, não é necessário que haja alto controle, e as transações podem ser feitas via mercado. À medida que a especificidade dos ativos cresce, é necessário que haja um maior controle sobre a transação, que pode ser proporcionado tanto pelo estabelecimento de contratos com salvaguardas específicas, quanto pela integração vertical.

Os produtos agrícolas em função de sua perecibilidade, possuem alta especificidade temporal. Dessa forma, as variações na estabilidade desses produtos e nos custos de sua preservação assumem decisiva importância nos determinantes das formas organizacionais de suas transações. Outra importante característica dos produtos agrícolas é a especificidade de lugar, que torna a localização geográfica altamente importante. À medida que o processamento reduz as perdas oriundas desse tipo de especificidade, pode-se esperar que as unidades de transformação se localizem próximo às fontes de matéria-prima.

Outra particularidade das cadeias produtivas agroindustriais está relacionada à dispersão geográfica de sua produção. As disparidades dos processos produtivos tendem a elevar os custos de administração interna, o que torna 
relativamente ineficiente a integração vertical entre os segmentos agrícola e industrial. Observa-se, portanto, que há a predominância de contratos de longo prazo entre dois segmentos quando a especificidade de ativos é alta.

Existem diferentes cadeias produtivas dentro do agribusiness, que estão associadas a diferentes tipos de produtos. As características específicas da produção, processamento e comercialização de cada um desses produtos é que irá influenciar a estrutura de governança a ser adotada.

\section{ANÁLISE DAS TRANSAÇÕES ENTRE OS SEGMENTOS DA CADEIA PRODUTIVA}

A identificação das estruturas de governança das transações permite a definição de qual forma contratual será estabelecida pelas empresas; se tratar-se-á determinado contrato a partir de uma pura relação de mercado, se ocorrerá a forma mista contratual, ou se haverá a necessidade de integração vertical. As características específicas das transações que ocorrem entre os segmentos da cadeia vitivinícola é que irão condicionar a estrutura de governança a ser adotada em cada uma dessas transações.

Para a identificação das interações entre os segmentos da cadeia vitivinícola catarinense foram entrevistados especialistas de três vinícolas, que estão entre as maiores do estado, cada uma representando uma das regiões produtoras do estado (Região do Vale do Rio do Peixe, Região Carbonífera e Região do Planalto Catarinense), e representantes de instituições vinculadas ao setor. A seguir, serão detalhadas as interações entre os segmentos da cadeia identificadas a partir das entrevistas e verificadas as estruturas de governança mais comumente praticadas.

\subsection{Interações entre fornecedores de insumos e viticultores/vinicultores}

O segmento fornecedor de insumos para o cultivo vitícola pode tanto atender aos viticultores, quanto as vinícolas que produzem sua própria uva. Sua principal característica é a concorrência devido a elevada quantidade de empresas atuantes no mercado.

O fornecimento de mudas para a formação dos vinhedos é praticamente monopolizado por empresas estrangeiras, visto que a incipiente produção 
nacional apresenta problemas fitossanitários. Devido ao fato de Santa Catarina não possuir um viveiro com certificação sanitária, a maioria das mudas adquiridas pelos produtores - especialmente os de uvas viníferas - é proveniente de países como Itália, França, África e Uruguai e, em menor parte, do estado vizinho Rio Grande do Sul. Embora exista certo grau de especificidade, a compra das mudas é realizada via mercado devido à necessidade esporádica de aquisição do material e à razoável quantidade de fornecedores atuantes no mercado internacional. Já a disseminação das mudas entre os viticultores tradicionais se dá basicamente por meio de trocas entre os próprios produtores, não sendo realizadas transações comerciais.

Fornecedores de máquinas utilizadas no plantio, como tratores, bem como de arames e de madeira, são facilmente encontrados no mercado, havendo inclusive certa concorrência setorial. O mesmo ocorre com os fornecedores de fertilizantes e defensivos agrícolas, que existem em grande número no mercado; a maioria realiza visitas às vinícolas oferecendo até mesmo prestação de assessoria para análise folhar e de solo, além de freqüentemente disponibilizarem amostras grátis de seus produtos.

Embora haja freqüência em algumas transações desse segmento, observa-se uma tendência à comercialização via mercado, viabilizada pelo número de concorrentes e conseqüente possibilidade de negociação de preços por parte dos produtores.

\subsection{Interações entre fornecedores de insumos e vinícolas}

Os fornecedores de insumos para os processos de vinificação e de engarrafamento apresentam características distintas entre si, dessa forma, diferentes tipos de contratos são estabelecidos entre esse segmento e as vinícolas.

Os insumos de maquinário para vinificação, como tanques de aço inox, prensadeiras e engarrafadeiras, são oferecidos em larga escala no mercado, especialmente por empresas estrangeiras. Entretanto, recentemente a indústria nacional vem se especializando e elevando a oferta desses tipos de bens. Já para a aquisição de compostos químicos como enzimas, leveduras e clarificantes, as vinícolas são obrigadas a recorrer apenas a fornecedores estrangeiros, devido à carência de tais produtos no mercado nacional. 
O segmento fornecedor de garrafas de vidro apresenta grande concentração de mercado, sendo dominado por duas principais empresas, Sangoban (Santa Marina) e Cisper. Os entrevistados apontam tais empresas como pouco diversificadas no que tange ao aspecto visual das garrafas, freqüentemente apresentando problemas de fornecimento, e, além disso, pouco aptas a negociações de preços. Diante disso, algumas empresas vêm buscando alternativas como a aquisição de garrafas importadas da França ou Chile.

Outro ponto de estrangulamento para as vinícolas encontra-se na aquisição de rolhas. Embora exista razoável número de empresas atuando nesse segmento, a principal matéria-prima, a cortiça, é importada principalmente da Espanha e de Portugal, o que torna as vinícolas suscetíveis às oscilações cambiais e às elevadas taxas de importação. Mais um insumo importado que vem impactando nas despesas dos vinicultores são as barricas de carvalho, que em toda sua vida útil possuem a capacidade de vinificar em média apenas 675 litros de vinho, e após três safras tornam-se inadequadas para uso. Em 2005, segundo dados da Síntese Anual da Agricultura de Santa Catarina, custavam aproximadamente 960 dólares, sem contar os impostos de importação (EPAGRI, 2006)

Rótulos e caixas de papelão são geralmente adquiridos com os mesmos fornecedores, pois a maioria das vinícolas possui contratos de longo prazo para o fornecimento dos materiais, que são em sua maioria personalizados com os logotipos das empresas.

Como a maioria das compras das empresas concentra-se no mês de janeiro (devido a época da vindima), tem-se observado uma incipiente tendência à compra cooperada visando a redução dos preços e o aumento no poder de negociação, especialmente por parte das vinícolas de menor porte. Segundo o relato do entrevistado Renato Mariot Damian, sócio-gerente da Vitivinícola Urussanga, a iniciativa vem sendo adotada pelas empresas da região, tendo a Associação dos Produtores da Uva e do Vinho Goethe (PROGOETHE) como mediadora das negociações. Além disso, a Associação Catarinense dos Produtores de Vinhos Finos de Altitude (ACAVITIS) já vem estudando a possibilidade de realização de compras cooperadas entre seus associados.

Embora não sejam firmados contratos formais, geralmente as vinícolas procuram adquirir seus insumos com os mesmos fornecedores, buscando a manutenção da freqüência e diminuição das incertezas nas transações, 
minimização dos custos de produção, além da conservação do padrão de qualidade na produção. Entretanto, em alguns casos, como na aquisição de rolhas e garrafas, as empresas ficam vulneráveis às oscilações cambiais, e ao poder oligopolístico de algumas empresas.

\subsection{Interações entre viticultores e vinícolas}

A maioria das vinícolas catarinenses de médio e grande porte, especialmente as situadas no pólo produtivo de São Joaquim, produz quase toda a uva de que necessita, em média apenas 15\% do total de uvas vinificadas pelas empresas são negociadas com viticultores, demonstrando uma tendência à verticalização entre os segmentos. Dentre as vinícolas de menor porte, produtoras de vinhos de mesa - destacadamente as situadas nas regiões de produção tradicional (Carbonífera e do Vale do Rio do Peixe) ao contrário, predominam as aquisições via mercado. Isso ocorre, devido à natureza acidentada de seus terrenos, que não permite o plantio em larga escala, e à grande oferta de uvas americanas, que proporciona às vinícolas maior poder de barganha junto aos produtores.

A tendência à integração vertical da produção é verificada especialmente em vinícolas voltadas à elaboração de vinhos finos, devido às especificidades dos ativos (uvas viníferas) e de capital humano (necessidade de especialistas), e à aplicação de cuidados especiais, como a aquisição de mudas importadas.

Já nas regiões tradicionais, onde a maior parte das matérias-primas é adquirida de produtores, as negociações são permeadas pela incerteza e pelo comportamento oportunista por parte dos produtores, pois geralmente não são firmados contratos formais, o que viabiliza o rompimento do acordado a qualquer tempo. Entretanto, pelo fato das vinícolas comprarem volumes grandes em relação às vendas dos viticultores, acabam por apresentar maior poder de barganha, reduzindo as margens do produtor, o que somente faz fomentar o comportamento oportunístico já mencionado.

Raramente são firmados contratos de parceria entre produtores e vinícolas, em geral estas prestam apenas algumas orientações ao viticultor quanto às formas de cultivo exigidas e quanto a produtividade máxima por videira, orientações essas que nem sempre são cumpridas. 


\subsection{Interações entre vinícolas e canais de distribuição}

A maioria das vinícolas catarinenses possui ponto de venda direto ao consumidor, situados em anexo à empresa, onde além da venda de vinhos, também é possível a degustação de pratos típicos italianos. Esse fenômeno de exploração do turismo do vinho vem se popularizando entre as principais vinícolas, pois além de divulgar a marca, incentiva o consumo da bebida.

Vendas para grandes atacadistas como super e hipermercados vem sendo evitadas pela maioria das vinícolas catarinenses devido à significativa redução das margens de lucro, e às inúmeras exigências apresentadas pelas redes, como contratos de longo prazo, exclusividade no fornecimento, elevado volume de produto, chegando a solicitar que a primeira compra seja em consignação, ou até mesmo gratuita para análise de giro do produto. Algumas empresas adotam a estratégia de segmentação de mercado, negociando apenas algumas linhas de produtos com os supermercados, sendo as de maior valor agregado comercializadas somente nos pontos de venda próprios.

Algumas vinícolas se utilizam de contratos de representação, firmados com lojas especializadas, empórios, e restaurantes que recebem o produto com preços competitivos e que atuam como canais de distribuição para as empresas.

Observa-se que, em geral, na cadeia produtiva vitivinícola os segmentos consumidores exercem maior poder de barganha perante seus fornecedores, demonstrando dessa forma, uma tendência de aumento de poder dos agentes a jusante, salvo algumas exceções onde os fornecedores apresentam excessivo poder de mercado.

\section{CONSIDERAÇÕES FINAIS}

O estado de Santa Catarina apresenta dois tipos de vitiviniculturas distintas. Uma composta pelas regiões Carbonífera e do Vale do Rio do Peixe, baseadas na elaboração de vinhos de mesa, produzidos em sua maioria por empresas de pequeno porte, com o uso intensivo de mão-de-obra familiar, e em terrenos bastante acidentados, que inviabilizam a implantação de uma viticultura mecanizada. Por outro lado, a região do Planalto Catarinense caracteriza-se pela incipiente produção de vinhos finos de altitude, elabo- 
rados sob os mais elevados padrões de qualidade e tecnologia, produzidos por empresas de maior porte com grandes investimentos de capital.

As diferenças entre as "vitiviniculturas" existentes no estado são potencialmente acentuadas quando se trata do perfil de governança adotado por cada uma. As regiões tradicionais (Carbonífera e do Vale do Rio do Peixe) se utilizam sistematicamente das aquisições tanto de insumos produtivos quanto de matérias-primas via mercado, seja devido às condições de seus terrenos bastante acidentados, que dificultam o cultivo em larga escala, seja pela natureza dos vinhos produzidos, elaborados a partir de variedades americanas, mais amplamente disponíveis no mercado. Devido à natureza das transações, as relações entre dois dos mais importantes segmentos da cadeia, o viticultor e o vinicultor, acabam sendo prejudicadas por comportamentos oportunistas que enfraquecem as transações, representando um significativo ponto de estrangulamento para a cadeia produtiva vitivinícola.

A falta de cooperação entre os dois elos da cadeia implica não somente na incerteza quanto à entrega do produto e na dificuldade de negociações dos preços, mas principalmente no entrave ao desenvolvimento do segmento produtor de vinhos de mesa. Isso ocorre porque há divergência nos interesses dos viticultores que prezam pela quantidade, ou seja, quanto maior a produtividade dos parreirais, maior o retorno financeiro, enquanto que os vinicultores que prezam pela qualidade de seus vinhos, dão preferência a videiras cuja produtividade seja menor, mas que produzam uvas de maior qualidade, com maior concentração de açúcar, necessárias para a elaboração de um bom vinho.

Já na região do Planalto Catarinense predomina a verticalização da produção à montante. A especificidade dos ativos necessários para a elaboração de vinhos finos, bem como a especificidade de capital humano qualificado, são fatores determinantes para a verticalização da produção. Dessa forma, observa-se que a maioria das vinícolas instaladas na região tende a produzir toda a uva de que necessitam, e muitas também verticalizam à jusante, visto que possuem pontos de venda a varejo próprios e evitam a comercialização com grandes atacadistas.

As dificuldades de negociação com grandes canais de distribuição foi apontada como um dos principais pontos de estrangulamento da cadeia, pois devido a seu elevado poder de mercado, os atacadistas se utilizam de 
diversas exigências para aquisição do produto, além de reduzirem drasticamente as margens de lucro dos produtores. Essa relação entre os segmentos industrial e distribuidor dificulta a inserção do produto nacional no mercado, contribuindo para a redução do consumo pelo fato de o consumidor desconhecer os vinhos produzidos no estado, e fomenta a crença de que somente os vinhos importados possuem qualidade.

\section{VITINICULTURE PRODUCTIVE CHAIN IN SANTA CATARINA: AN ANALYSIS OF TRANSACTION AMONG ITS SEGMENTS}

\section{Abstract}

The objective of this paper is to identify the characteristics of the transactions between different segments of the value chain of the vitiviniculture sector in Santa Catarina. We reviewed the main literature and conduct interviews with experts, institutions and businessmen in the sector. The results indicate that, in the traditional regions, inputs are purchased using the market, which increases the transaction costs and stimulate an opportunistic behavior of the agents in the value chain. On the other hand, in new productive regions, producers follow a vertical integration towards inputs due to the specificity of the assets needed to the production of high quality wines.

Keywords: vitiviniculture, governance structures, agribusiness value chains.

JEL Classification: Q13.

\section{REFERÊNCIAS}

AZEVEDO. Paulo Furquin. Nova Economia Institucional: Referencial Geral e Aplicações para a Agricultura. Agricultura em São Paulo, v.47, n. 1, p. 33-52, 2000. 
A cadeia produtiva de uvas e vinhos de Santa Catarina: uma análise das transações entre os seus segmentos

BATALHA, Mário Otávio. Gestão Agroindustrial. São Paulo: Atlas, 2001.

EPAGRI (Empresa de Pesquisa Agropecuária de Santa Catarina). Síntese Anual da Agricultura de Santa Catarina, 2006

FARINA, Elizabeth Maria Mercier Querino et al. Competitividade: mercado, estado e organizações. São Paulo: Singular, 1997.

FIANNI, Ronaldo. Teoria dos Custos de Transação. In: KUPFER, David; HASENCLEVER, Lia (Org.) . Economia Industrial: Fundamentos Teóricos e Práticos no Brasil. Rio de Janeiro: Campus, 2002.

IBRAVIN. (Instituto Brasileiro do Vinho). Disponível em <http://www. ibravin.org.br>. Acesso em: 17 de maio de 2007.

PESSALI, Huascar Fialho; FERNANDEZ, Rámon Gárcia. Teoria dos Custos de Transação e Abordagens Evolucionistas: Análise e Perspectivas de um Programa de Pesquisa Específico. Revista de Economia Política, v.21, n.2, abril/junho, p. 99-116, 2001.

PROGOETHE. (Associação dos Produtores da Uva e do Vinho Goethe). Disponível em: < http://www.proGoethe.com.br>. Acesso em 12 de fevereiro de 2008.

ZYLBERSZTAJN, Décio; NEVES, Marcos Fava. Conceitos gerais, evolução e apresentação do sistema agroindustrial. In: Economia e gestão dos negócios agroalimentares. São Paulo: Pioneira, 2000.

Artigo submetido em fevereiro de 2011 e aceito para publicação em junho de 2011. 